\title{
Role of Cold Balanced Salt Solution (BSS) in the Prophylaxis of Cystoid Macular Edema After Cataract Surgery: A Prospective Randomized Study
}

\author{
Alessandro Meduri ${ }^{\prime}{ }^{\prime}$ \\ Giovanni William Oliverio (D) ${ }^{\prime}$ \\ Loredana Bergandi $\left(\mathbb{D}^{2}\right.$ \\ Gabriella De Salvo (D) ${ }^{3}$ \\ Rino Frisina ${ }^{4}{ }^{4}$ \\ Cosimo Mazzotta (iD $)^{5,6}$ \\ Pasquale Aragona (D)
}

'Biomedical, Dental and Morphological and Functional Images Sciences Department, University of Messina, Messina, Italy; ${ }^{2}$ Department of Oncology, University of Torino, Turin, Italy; ${ }^{3}$ Eye Unit, University Hospital Southampton Foundation Trust. Southampton, UK; ${ }^{4}$ Department of Neurosciences - Ophthalmology, University of Padova, Padua, Italy; ${ }^{5}$ Departmental Ophthalmology Unit, Alta Val d'Elsa Hospital, Siena, Italy; ${ }^{6}$ Siena Crosslinking Center, Siena, Italy
Correspondence: Loredana Bergandi Department of Oncology, University of Torino, Via Santena 5 Bis, Turin, 10126, Italy

Tel +340116705843

Fax +340116705840

Email loredana.bergandi@unito.it
Purpose: To evaluate the postoperative effect on central retinal macular thickness of a cooled irrigating eye solution used during cataract surgery.

Patients and Methods: In this prospective, single-center study, 100 eyes of 50 patients (26 males and 24 females) were evaluated with spectral domain optical coherence tomography (SD-OCT) before and after phacoemulsification for senile cataract. Eyes were randomly divided into two groups based on the irrigating solution used during surgery: Group 1, 50 eyes received intraoperative irrigating solution at room temperature $\left(\sim 20.0 \pm 0.1{ }^{\circ} \mathrm{C}\right)$; and Group 2, 50 fellow eyes received cold intraoperative irrigating solution $\left(2.7 \pm 0.1^{\circ} \mathrm{C}\right)$. Changes in central macular thickness (CMT) were evaluated in both groups by SD-OCT macular raster scan for the nine Early Treatment of Diabetic Retinopathy Study (ETDRS) subfields and total macular volume, performed pre-surgery, and 1 and 4 weeks post-surgery. Results: Despite there being no significant differences in variables between the two groups preoperatively, significant increases in CMT were observed at 1 week after surgery in both groups ( $p=0.02$ and $p=0.03$, respectively), as well as in total macular volume $(p<0.0001$ and $p=0.02$, respectively). Inter-subgroup analysis showed a significant reduction in CMT $(p=0.03)$ and total macular volume $(p=0.001)$ at 1 week post-surgery in Group 2 compared to Group 1, whereas no significant differences were observed at 4 weeks.

Conclusion: The use of a cooled irrigating eye solution during phacoemulsification may be beneficial in preventing the possible development of postoperative macular thickening. Further clinical studies may support this finding.

Keywords: cataract surgery, cystoid macular edema, central macular thickness, spectral domain optical coherence tomography, phacoemulsification, cold intraoperative irrigating solution

\section{Introduction}

Cystoid macular edema (CME) following cataract surgery is a common and wellrecognized complication. CME may also occur in patients who do not present any risk factors, ${ }^{1,2}$ such as diabetic retinopathy and other retinal pathologies. ${ }^{3-5}$ The exact pathomechanism is not known and is likely to be multifactorial; ${ }^{6}$ however, surgical trauma to the iris, ciliary body, and lens epithelial cells causes release of phospholipids, and thereby release of prostaglandins or other inflammatory mediators. Indeed, the pathophysiology of CME in these cases includes upregulation of inflammatory mediators, infiltration of inflammatory cells, vascular dysfunction, and, finally, damage to retinal cells. ${ }^{7,8}$ 
The role played by cytokines, prostaglandins, and thromboxane in the inflammatory response in the anterior chamber after cataract surgery is well known. ${ }^{9-11}$ The inflammatory mediators stimulate the breakdown of the blood-retinal barrier, resulting in the accumulation of intraretinal fluid, leading to macular thickening and edema. $^{2}$ Topical non-steroidal anti-inflammatory drugs (NSAIDs) are usually designed to prevent CME after cataract surgery in patients at risk, not to treat inflammation of the posterior segment of the eye..$^{12,13}$

The aim of our study is to evaluate the role of intraoperative cold irrigating eye balanced salt solution (BSS) in influencing the central retinal thickness and, therefore, in preventing the possible development of postoperative CME (increase in retinal thickness of at least 10\% from baseline caused by multiple pseudocysts in the macula ${ }^{14}$ ). Indeed, this could be useful in understanding how to eliminate a modifiable risk factor for complications during phacoemulsification cataract surgery.

\section{Patients and Methods}

In this prospective, interventional, single-center study, 50 patients (26 males and 24 females) with a diagnosis of senile cataract, who underwent phacoemulsification at the Ophthalmology Department of the University Hospital "G. Martino" Messina, Italy, were randomly enrolled in the study between April 2019 and May 2019. Their mean age was 65 \pm 7.3 years (range $55-75$ years). The study was carried out in accordance with the Declaration of Helsinki for medical research involving human subjects and was approved by the local Ethical Committee, University Hospital "G. Martino" Messina, Italy (number 43/19-0006654). Informed and written consent was obtained from all patients agreeing to be included in this study, before undergoing cataract surgery.

Inclusion criteria were cataract of middle degree (stages 2-3) according to the classification of Lens Opacities Classification System III (LOCSIII), ${ }^{15}$ and age older than 55 years with no other ocular abnormalities. Exclusion criteria were patients with any pre-existing or coexisting corneal and retinal diseases, but also with pseudoexfoliation, shallow anterior chamber, glaucoma posterior synechiae, or any previous ocular surgery, subluxated or traumatic cataract.

The baseline ophthalmic examination performed preoperatively included slit-lamp evaluation, intraocular pressure (IOP), fundus examination, and a volumetric assessment of the central retinal using the "fast macular volume" preset, ${ }^{16}$ consisting of a 25 horizontal axial raster scan covering $20^{\circ} \times 20^{\circ}$ composed of 25 sections, spaced at $240 \mu \mathrm{m}$, and centered on the fovea, performed with a Spectralis ${ }^{\circledR}$ SD-OCT (Heidelberg Engineering, Heidelberg, Germany). The follow-up visits were then arranged for each patient 1 week and 4 weeks following phacoemulsification as per the local protocol and since the peak of CME occurs between 4 and 6 weeks after surgery. ${ }^{17}$ The follow-up function of the Spectralis was used to obtain comparative scans. The central retinal thickness, measured in the central $1.0 \mathrm{~mm}$ macular subfield, and volume measurements, total and for the nine ETDRS subfields, were obtained using Heidelberg Eye Explorer software (version 1.7.0.0; Heidelberg Engineering).

All patients were pretreated 3 days prior to the surgery with antiseptic solution, 1\% sodium hypochlorite bid (Septavis ${ }^{\circledR}$ spray; Medivis, CT, Italy), to the periorbital skin, and $0.3 \%$ ofloxacin $1 \mathrm{gtt}$ tid. Patients had instilled one drop of topical tropicamide and phenylephrine $(0.28 \quad \mathrm{mg} / 5.4 \quad \mathrm{mg})$ $\left(\right.$ Mydriasert $^{\circledR}$; Thèa Farma, Milan, Italy) 20 minutes before surgery.

The 100 eyes of the 50 patients were randomly distributed into two groups: Group 1, 50 eyes receiving intraoperative irrigating solution at room temperature $\left(\sim 20.0 \pm 0.1^{\circ} \mathrm{C}\right)$; and Group 2, 50 fellow eyes receiving cold intraoperative irrigating solution $\left(2.7 \pm 0.11^{\circ} \mathrm{C}\right)$. The use of a thermal coat of ice and water ensured that there was no temperature variation during the surgery. ${ }^{18}$ The anterior chamber temperature variation, measured with a thermal camera during phacoemulsification in the presence of cold solution, was about of $6-8^{\circ} \mathrm{C}$ less than the variation measured in the presence of ultrasound and room temperature solution. ${ }^{19}$ To meet the Ethical Committee board approval and amendments, and to reduce the interpersonal variability in interpretation of the results, ${ }^{20}$ each patient was attributable to both groups, as one eye was treated with the room temperature solution and the fellow eye with the cooled solution. The surgery was carried out by the same surgeon (AM) using an OPMI Lumera 700 microscope (Carl Zeiss Vision Italia, Varese, Italy) and a SIGNATURE ${ }^{\circledR}$ Phacoemulsification System (Abbott Medical Optics, Johnson \& Johnson Vision Medical, Pomezia, Rome, Italy). A standardized phacoemulsification with an intraocular lens implant surgical technique was performed. An incision of $1 \mathrm{~mm}$ was made in the clear cornea. Subsequently, an injection of Viscoat (Alcon Laboratories, Fort Worth, TX, USA) was performed. Then, the high-molecular weight ProViscs (Alcon Laboratories) was injected into the anterior chamber, thus moving the Viscoat up, towards the cornea, to protect the layer of endothelium. Afterwards, the surgeon created a $2.2 \mathrm{~mm}$ temporal tunnel, on the clear cornea, then a nick in 
the anterior capsule using a cystotome, thus carrying out a $5 \mathrm{~mm}$ capsulorhexis. After a safe hydrodissection, the surgeon carried out phacoemulsification using the SIGNATURE (Abbott Medical Optics) phacoemulsificator, using standardized surgical techniques. The following parameters were used: flow $25 \mathrm{~mL} /$ minute, vacuum 350, and ultrasound energy $30 \%(\mathrm{~J})$ (the last parameter was variable on the basis of the cataract hardness), as previously described. ${ }^{18}$ The effective phacoemulsification time (EPT), that is, the cumulative ultrasound energy used intraoperatively during the phacoemulsification procedure, was also calculated. Subsequently, a complete cortex removal was carried out by manual irrigation and aspiration, followed by IOL implantation in the capsular bag; the residual viscoelastic material was then removed by manual irrigation and aspiration.

After the surgery, each patient was treated for 4 weeks qid with artificial tears (Ialuvit ${ }^{\circledR}$; Alfa Intes Industria Terapeutica Splendore, Naples, Italy), with a combination of cortisone and antibiotics (betamethasone $2 \mathrm{mg} / \mathrm{mL}$, chloramphenicol $5 \mathrm{mg} / \mathrm{mL}$ ) gtt and bromfenac $0.9 \mathrm{mg} / \mathrm{mL}$ gtt tid. None of the patients had any intraoperative complications.

\section{Statistical Analysis}

The central macular thickness (CMT) was considered as the primary outcome measure for the study, whereas the IOP, the best corrected visual acuity (BCVA), and the endothelial cell count were considered as secondary outcome measures.

A Lilliefors test was performed for every set of data, using the MATLAB ${ }^{\circledR}$ lillietest function (The MathWorks, C1994 2019; Lilliefors test, MATLAB MathWorks, Italy) to ensure that the collected macular measurements followed a normal distribution, after eliminating the outliers of the various datasets using the MATLAB isoutlier function. As all the obtained $p$-values were $<0.001$, non-parametric tests, namely the Kruskal-Wallis ANOVA test and the Wilcoxon test (MathWorks, C1994-2019 Kruskal-Wallis test; and Wilcoxon test, MATLAB, MathWorks, Italy), were used. The first is the equivalent non-parametric test of the one-way ANOVA and allows comparison of multiple different, independent datasets of the same variable, to evaluate whether they follow the same distribution (null hypothesis). ${ }^{21}$ The second is the equivalent of the non-parametric test of the $t$-test, which compares two different independent datasets of the same variable to evaluate whether they follow the same distribution (null hypothesis). If the $p$-value returned by one of the functions is higher than a specified threshold (it was set at 5\% significance level), the specific test fails to reject the null hypothesis. This means that the different datasets refer to the same distribution with a probability proportional to the $p$-value. A power calculation was done using StatSoft software considering only the primary outcome, the CMT. The power of the study, given significant differences in both intragroup and intergroup comparisons, was calculated to be $86 \%$ and $85 \%$, respectively, with $\alpha=0.05$ and 50 random eyes for each group enrolled.

\section{Results}

Preoperative clinical characteristics of Group 1 patients receiving intraoperative irrigating solution at room temperature $\left(\sim 20.0 \pm 0.1^{\circ} \mathrm{C}\right)$ and of Group 2 receiving cold intraoperative irrigating solution $\left(2.7 \pm 0.1^{\circ} \mathrm{C}\right)$ are reported in Table 1. No statistically significant differences were observed between the two groups in preoperative parameters such as axial length, anterior chamber depth, IOP, BCVA, or endothelial cell count.

In Group 1, there were 42 eyes with stage II cataract and eight eyes stage III cataract, whereas 40 eyes presented stage II cataract and 10 eyes stage III cataract in Group 2. After cataract surgery, the mean EPT was 7.16 \pm 2.55 in Group 1 and $7.35 \pm 2.83$ in Group $2(p=0.27)$.

\section{OCT Parameters}

Preoperatively, the mean CMT was $216.9 \pm 7.9 \mu \mathrm{m}$ in Group 1 , whereas in Group 2 it was $217.5 \pm 8.3 \mu \mathrm{m}(p=0.21)$. At 1 week post-cataract surgery, there was a significant increase in CMT ( $p=0.02)$, as well as temporal, nasal, superior, and inferior inner macular thickness, and temporal and nasal outer macular thickness, in Group 1 (Table 2). In Group 2, significant increments in CMT were noted $(p=0.03)$; in additional, superior, inferior inner, and temporal outer macular thicknesses were significantly increased (Table 2).

Moreover, statistically significant changes in total macular volume were observed at 1 week in both groups $(p<0.0001$ and $p=0.02$, respectively). Furthermore, at 1 week after surgery, statistically significant differences was observed in CMT $(p=0.03)$ as well as in total macular volume ( $p=0.001$ ) when comparing Group 1 and Group 2 patients; however, at 4 weeks these changes were not statistically significant ( $p=0.07$ and $p=0.24$ ) (Table 2). None of the eyes in the two groups developed CME 4 weeks postphacoemulsification.

\section{Visual Acuity and Safety Parameters}

At 1 and 4 weeks after surgery, there was a significant change in BCVA in both groups $(p<0.0001)$, whereas no significant differences were observed at 1 and 4 weeks between the two groups (Table 3 ). At the end of follow- 
Table I Preoperative Clinical Characteristics of Eyes in Group I Receiving Intraoperative Irrigating Solution at Room Temperature $\left(\sim 20.0 \pm 0.1^{\circ} \mathrm{C}\right)$ and in Group 2 Receiving Cold Intraoperative Irrigating Solution $\left(2.7 \pm 0.1^{\circ} \mathrm{C}\right)$

\begin{tabular}{|l|c|c|c|}
\hline Parameters & Group I (n=50) & Group 2 (n=50) & p-Value \\
\hline Axial length $(\mathrm{mm})$ & $23.5 \pm 7.2$ & $23.7 \pm 8.1$ & 0.09 \\
\hline ACD $(\mathrm{mm})$ & $3.5 \pm 0.5$ & $3.4 \pm 0.6$ & 0.21 \\
\hline Endothelial cell count $(\mathrm{n})$ & $2453.1 \pm 275$ & $2471 \pm 289$ & 0.08 \\
\hline BCVA (logMAR) & $0.53 \pm 0.22$ & $0.52 \pm 0.26$ & 0.41 \\
\hline IOP $(\mathrm{mmHg})$ & $14.5 \pm 2$ & $14.9 \pm 2.7$ & 0.27 \\
\hline Central subfield macular thickness $(\mu \mathrm{m})$ & $216.9 \pm 7.9$ & $217.5 \pm 8.3$ & 0.21 \\
Temporal inner & $296.3 \pm 11.7$ & $294.1 \pm 12.4$ & 0.09 \\
Nasal inner & $299.6 \pm 9.1$ & $300.7 \pm 7.9$ & 0.17 \\
Superior inner & $297.4 \pm 9.2$ & $299.4 \pm 9.5$ & 0.07 \\
Inferior inner & $288.4 \pm 8.9$ & $287.7 \pm 8.2$ & 0.15 \\
Temporal outer & $250.6 \pm 10.5$ & $254.9 \pm 12.9$ & 0.06 \\
Nasal outer & $282.6 \pm 6.4$ & $284.9 \pm 6.4$ & 0.09 \\
Superior outer & $292.9 \pm 3.8$ & $294.5 \pm 4.9$ & 0.12 \\
Inferior outer & $272.4 \pm 6.7$ & $273.8 \pm 7.3$ & 0.18 \\
\hline Total macular volume $\left(\mathrm{mm}^{3}\right)$ & $8.63 \pm 0.29$ & $8.61 \pm 0.32$ & 0.79 \\
\hline
\end{tabular}

Note: All data are expressed as mean \pm standard deviation.

Abbreviations: ACD, anterior chamber depth; BCVA, best corrected visual acuity; logMAR, logarithm of the minimum angle of resolution; IOP, intraocular pressure.

up, 24 eyes (48\%) gained more than 3 Snellen lines, 16 eyes (32\%) gained 2 Snellen lines, and 10 eyes (20\%) gained 1 Snellen line in Group 1; whereas in Group 2, 28 eyes $(56 \%)$ gained 3 or more Snellen lines, 14 eyes (28\%) gained 2 Snellen lines, and eight eyes (16\%) gained 1 Snellen line. No eyes lost lines at the end of follow-up in either group.

In addition, there were significant decreases in the endothelial cell count in both groups after surgery, but, in accordance with our previous data, ${ }^{18}$ the decrease was significantly higher in Group $1(p<0.0001)$ (Table 3), where a reduction in the loss of endothelial cells was observed. No changes in IOP were recorded throughout the follow-up period in either group (Table 3).

\section{Discussion}

This prospective randomized study opens up new perspectives for the use of the cooled irrigating eye solution during phacoemulsification in preventing the possible development of postoperative macular thickening. The most frequent postoperative complication of cataract surgery is CME, which, in most cases, evolves to a spontaneous resolution. In many cases after cataract surgery, it is possible to detect a subclinical increase in macular thickness; usually, a higher incidence of edema occurs 4-6 weeks after the phacoemulsification, with a recovery to baseline values around 6 months after surgery. ${ }^{22,23}$ However, visual loss can affect a few patients. $^{24}$

Many studies have reported the effects of phacoemulsification on the posterior structures, and, in particular, on the retinal and choroidal thickness of the eye., ${ }^{6,25-29}$ Indeed, clinical evidence shows an important increase in the perifoveal and foveal thickness of the retina, detected using OCT, in patients who have undergone cataract surgery $^{30}$ and Nd:YAG laser capsulotomy. ${ }^{31}$ Gharbiya et al demonstrated a progressive increase in macular thickness from the first week until the sixth month in patients who had undergone uneventful phacoemulsification. ${ }^{32}$ These data are in keeping with those of our study only at 1 week post-surgery, where a significant increase in CMT was detected by SD-OCT.

Until now, the possible beneficial effect of a cold eye irrigating solution during phacoemulsification on CMT has not been exhaustively investigated. Edelhauser et $\mathrm{al}^{33}$ demonstrated that using a hypothermic solution during surgery can lead to positive effects on the human corneal and vascular tissues of the retina, and Hoffman et $\mathrm{al}^{34}$ reported the beneficial effects of an intraoperative cooled irrigating solution on the tissues of the eye. However, neither of these studies 


\begin{tabular}{|c|c|c|c|c|c|c|c|c|c|c|c|}
\hline 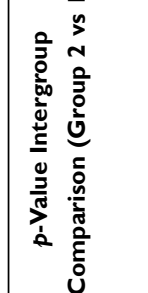 & 苂 & $\frac{1}{3}$ & & 柆言 & 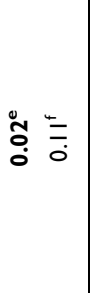 & $\frac{5}{8}$ & ةً & 咅 & 客言 & 象敩 & 亏ั) \\
\hline 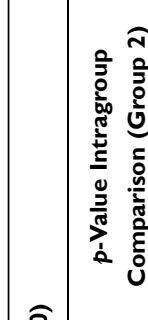 & $\dddot{g}$ & 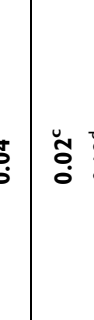 & & 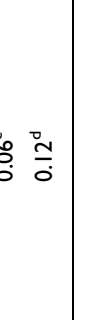 & 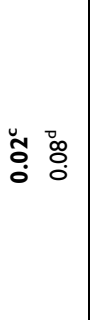 & 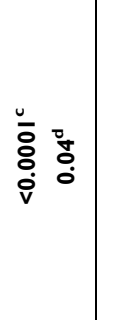 & 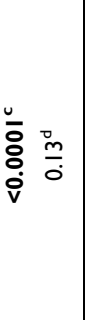 & : & 然妻 & 㕸 & 岁: \\
\hline 产 & 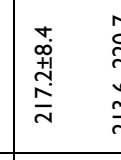 & $\frac{7}{\frac{7}{3}}$ & 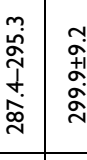 & 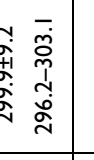 & 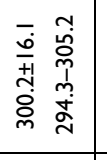 & 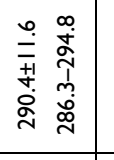 & 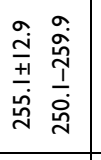 & 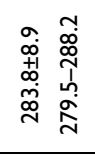 & 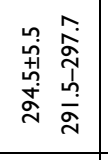 & 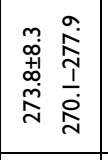 & 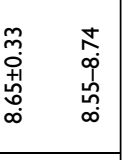 \\
\hline 薏 & & $\frac{8}{8}$ & & 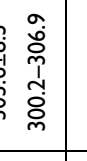 & 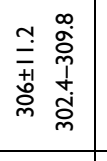 & 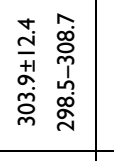 & 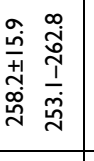 & 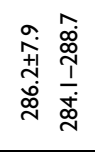 & 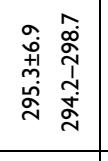 & 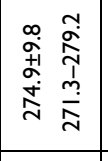 & 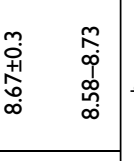 \\
\hline 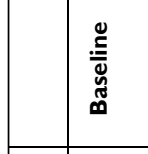 & 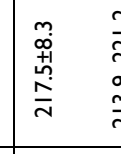 & 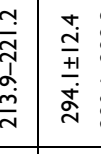 & & 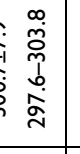 & 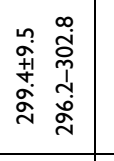 & 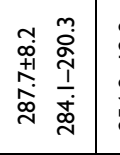 & 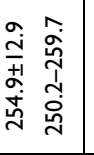 & 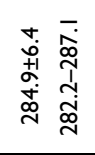 & 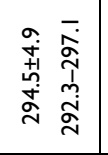 & 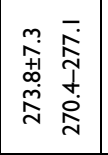 & 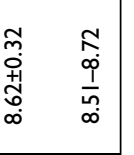 \\
\hline 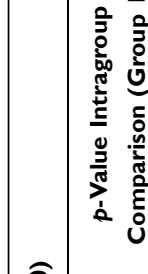 & \%ั & $\frac{\overbrace{0}^{\circ}}{2}$ & & 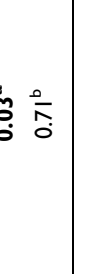 & : & 亏亏亏 & 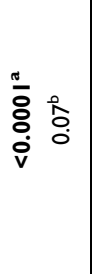 & 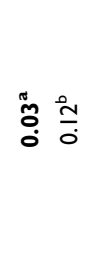 & $\frac{6}{2}=\frac{8}{2}$ & 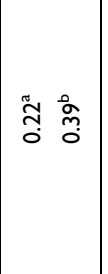 & 亏ั) \\
\hline 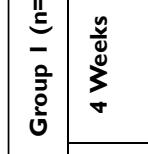 & 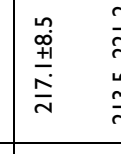 & 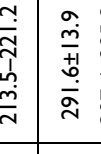 & & $\begin{array}{l}0 \\
\end{array}$ & 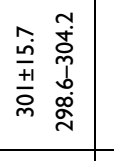 & 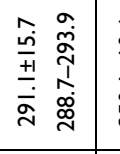 & 善 & 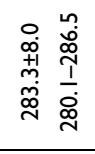 & 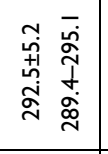 & 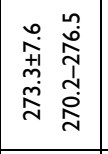 & 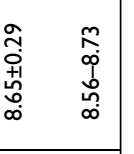 \\
\hline 产 & $\begin{array}{l}\alpha \\
\frac{\alpha}{y} \\
z \\
z\end{array}$ & 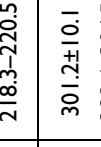 & & 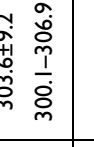 & 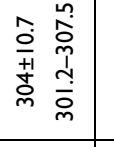 & 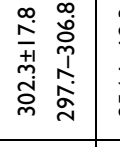 & 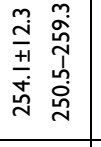 & 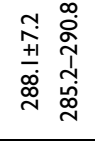 & 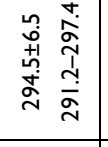 & 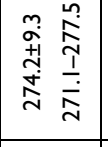 & 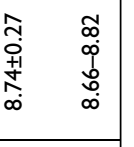 \\
\hline $\begin{array}{l}\text { 量 } \\
\text { 音 }\end{array}$ & 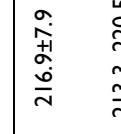 & 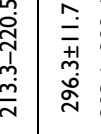 & 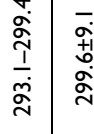 & $\begin{array}{l}0 \\
\end{array}$ & 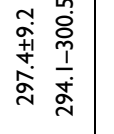 & 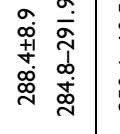 & 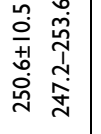 & 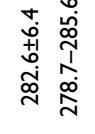 & 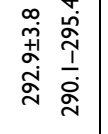 & 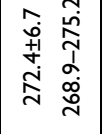 & 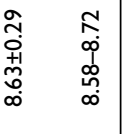 \\
\hline & & & & & & & & & & & 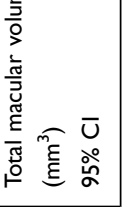 \\
\hline
\end{tabular}




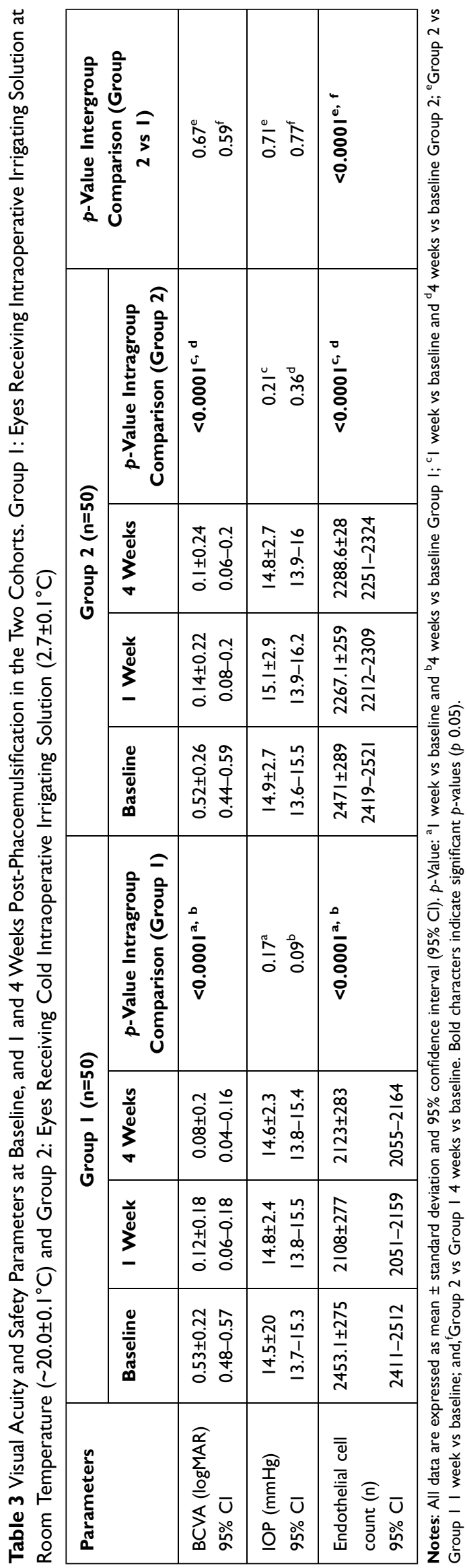

investigated the effect of hypothermia on retinal and choroidal thickness, or intraocular inflammation. In contrast, Praveen et $\mathrm{al}^{35}$ showed that the use of moderately cooled BSS had no detectable effect on the central corneal thickness and anterior segment after phacoemulsification, and demonstrated a benefit on the outcome of the surgery. Meduri et al demonstrated the efficacy of treatment with cold irrigation solution on the reduction of anterior chamber flare, pain, and conjunctival hyperemia at 1 day after phacoemulsification, suggesting that the cooling procedure was fully effective in controlling early postoperative inflammation. ${ }^{19}$

The damage caused by the light, the vitreoretinal traction, the timing, and the energy of the phacoemulsification, and, above all, the increased levels of cytokines, prostaglandins, and thromboxane, may be linked to the fluid retention, ${ }^{36}$ thus influencing the progression of the edema. Indeed, CME is often observed after complicated cataract surgery, but may also occur in uncomplicated surgeries. ${ }^{4}$ The formation of fluid-filled pseudocystic spaces in the retinal layers of the retina affects $0.2-14 \%$ of cases and, notably, it is increased in patients affected by uveitis and diabetes, which are well known as inflammatory processes. ${ }^{37}$ In the retina and choroid of rodent models, the gene expression and, consequently, the protein secretion of pro-inflammatory factors were studied, confirming the role of cataract surgery in the onset of an inflammatory process of the posterior pole. ${ }^{38}$ Notably, the involvement of an inflammatory status which leads to macular edema is also underlined by the fact that nepafenac $0.3 \%$, an anti-inflammatory drug, was efficacious in reducing macular thickness, measured by SD-OCT, compared to a placebo 5 weeks postoperatively. ${ }^{39}$ Moreover, anti-inflammatory prophylaxis with nepafenac in diabetic patients undergoing cataract surgery improves postoperative outcomes. ${ }^{39}$

In our study, an increased macular thickness at 1 week after cataract surgery was seen in both groups; these changes were significantly pronounced in eyes that received a room temperature BSS. Indeed, in the first days after cataract surgery, it is plausible to observe the higher expression and release of pro-inflammatory mediators. ${ }^{38}$

Our findings showed a beneficial role of the cooled BSS during cataract surgery, reducing the inflammatory reaction and, consequently, the breakdown of the bloodretinal barrier that may lead to macular edema. However, at 4 weeks no significant changes in CMT were observed in either group. This could also be related to the reduced 
inflammation as an effect of the anti-inflammatory treatment with bromfenac throughout the follow-up period. Although an increased CMT was observed in both groups, no cases of CME were recognized 4 weeks postphacoemulsification.

Moreover, after surgery, there was a significant reduction in the endothelial cell count in eyes that received a room temperature BSS, suggesting the induction of damage in corneal cells during phacoemulsification; in contrast, reduced surgical stress using cooled BSS during phacoemulsification was demonstrated by our previous clinical findings. ${ }^{18}$

\section{Conclusion}

Our previous study demonstrated that the use of a cold irrigation solution plays a pivotal role in reducing or even preventing the damage to corneal endothelial cells during phacoemulsification when ultrasound has been used at low power in patients with cataracts of degree 3 or higher, ${ }^{18}$ classified according to the LOCSIII. ${ }^{15}$

Taken together, our clinical evidence shows that the use of a cold irrigating eye solution plays a protective role on the macula, and thus the development of CME in eyes undergoing cataract surgery. However, although we achieved encouraging results with this low-cost procedure, the study presents a few limitations, such as the small number of eyes, short follow-up, and the procedures being performed by a single surgeon. A longer randomized clinical study is necessary to confirm the validity of this investigation. Nevertheless, this study may pave the way towards the easy diffusion of this user-friendly technique.

\section{Funding}

The authors received no financial support for the research, authorship, and publication of this article. Dr De Salvo received consultancy fees from Heidelberg Engineering, Novartis, Allergan, and Bayer, not related to this manuscript.

\section{Disclosure}

The authors declare that there is no conflict of interest.

\section{References}

1. Kim SJ, Bressler NM. Optical coherence tomography and cataract surgery. Curr Opin Ophthalmol. 2009;20(1):46-51. doi:10.1097/ ICU.0b013e3283199162

2. Sheppard JD. Topical bromfenac for prevention and treatment of cystoid macular edema following cataract surgery: a review. Clin Ophthalmol. 2016;10:2099-2111. doi:10.2147/OPTH.S86971
3. Ilveskoski L, Taipale C, Holmström EJ, Tuuminen R. Macular edema after cataract surgery in eyes with and without pseudoexfoliation syndrome. Eur J Ophthalmol. 2019;29(5):504-509. doi:10.1177/ 1120672118799622

4. Sahin M, Cingü AK, Gözüm N. Evaluation of cystoid macular edema using optical coherence tomography and fundus autofluorescence after uncomplicated phacoemulsification surgery. $J$ Ophthalmol. 2013;2013:376013. doi:10.1155/2013/376013

5. Daruich A, Matet A, Moulin A, et al. Mechanisms of macular edema: beyond the surface. Prog Retin Eye Res. 2018;63:20-68.

6. Abdellatif MK, Ebeid WM. Variations in choroidal and macular thickness maps after uneventful phacoemulsification. Semin Ophthalmol. 2018;33(5):719-725. doi:10.1080/08820538.2017.1417453

7. Hermankova B, Kossl J, Bohacova P, et al. The immunomodulatory potential of mesenchymal stem cells in a retinal inflammatory environment. Stem Cell Rev Rep. 2019;15(6):880-891. doi:10.1007/ s12015-019-09908-0

8. Wong TY, Cheung CMG, Larsen M, Sharma S, Simó R. Diabetic retinopathy. Nat Rev Dis Primers. 2016;2:16012. doi:10.1038/ nrdp. 2016.12

9. Jiang J, Shihan MH, Wang Y, Duncan MK. Lens epithelial cells initiate an inflammatory response following cataract surgery. Invest Ophthalmol Vis Sci. 2018;59(12):4986-4997. doi:10.1167/iovs.1825067

10. Chu L, Wang B, Xu B, Dong N. Aqueous cytokines as predictors of macular edema in non-diabetic patients following uncomplicated phacoemulsification cataract surgery. Mol Vis. 2013;19:2418-2425.

11. Chen H, Lin H, Zheng D, Liu Y, Chen W, Liu Y. Expression of cytokines, chmokines and growth factors in patients undergoing cataract surgery with femtosecond laser pretreatment. PLoS One. 2015;10(9):e0137227. doi:10.1371/journal.pone.0137227

12. Asai T, Nakagami T, Mochizuki M, Hata N, Tsuchiya T, Hotta Y. Three cases of corneal melting after instillation of a new nonsteroidal anti-inflammatory drug. Cornea. 2006;25(2):224-227. doi:10.1097/ 01.ico.0000177835.93130.d4

13. Reviglio VE, Rana TS, Li QJ, Ashraf MF, Daly MK, O'Brien TP. Effects of topical nonsteroidal antiinflammatory drugs on the expression of matrix metalloproteinases in the cornea. J Cataract Refract Surg. 2003;29(5):989-997. doi:10.1016/S0886-3350(02)01737-6

14. Aaronson A, Achiron A, Tuuminen R. Clinical course of pseudophakic cystoid macular edema treated with nepafenac. J Clin Med. 2020;9(9):3034. doi:10.3390/jcm9093034

15. Chylack LT, Wolfe JK, Singer DM, et al. The lens opacities classification system III. The Longitudinal Study of Cataract Study Group. Arch Ophthalmol. 1993;111(6):831-836.

16. Comyn O, Heng LZ, Ikeji F, et al. Repeatability of Spectralis OCT measurements of macular thickness and volume in diabetic macular edema. Invest Ophthalmol Vis Sci. 2012;53(12):7754-7759. doi:10.1167/iovs.12-10895

17. Yonekawa Y, Kim IK. Pseudophakic cystoid macular edema. Curr Opin Ophthalmol. 2012;23(1):26-32. doi:10.1097/ICU.0b013e328 $34 \mathrm{~cd} 5 \mathrm{f} 8$

18. Meduri A, Aragona P, Testagrossa B, et al. An alternative approach to cataract surgery using BSS Temperature of $2.7^{\circ} \mathrm{C}$. Applied Sciences. 2020;10(8):2682.

19. Meduri A, Bergandi L, Oliverio GW, et al. The cold eye irrigation BSS solution used during phacoemulsification reduces post-surgery patients discomfort preventing the inflammation. Eur J Ophthalmol. 2021. doi: $10.1177 / 11206721211018377$

20. Schmidt W-P. Randomised and non-randomised studies to estimate the effect of community-level public health interventions: definitions and methodological considerations. Emerg Themes Epidemiol. 2017;14:9. doi:10.1186/s12982-017-0063-5

21. Kruskal WH, Wallis WA. Use of ranks in one-criterion variance analysis. J Am Stat Assoc. 1952;47(260):583-621. doi:10.1080/ 01621459.1952 .10483441 
22. Agange N, Mosaed S. Prostaglandin-induced cystoid macular edema following routine cataract extraction. $J$ Ophthalmol. 2010;20 10:690707. doi:10.1155/2010/690707

23. Hwang HS, Ahn YJ, Lee HJ, Kim MS, Kim EC. Comparison of macular thickness and inflammatory cytokine levels after microincision versus small incision coaxial cataract surgery. Acta Ophthalmol. 2016;94(3):e189-194. doi:10.1111/aos.12716

24. Walkden A, Porter LF, Morarji J, Kelly SP, Sioras E. Pseudophakic cystoid macular edema and spectral-domain optical coherence tomography-detectable central macular thickness changes with perioperative prostaglandin analogs. J Cataract Refract Surg. 2017;43 (8):1027-1030. doi:10.1016/j.jcrs.2017.05.029

25. Kurt A, Kılıç R. The effects of uncomplicated cataract surgery on retinal layer thickness. $J$ Ophthalmol. 2018;2018:7218639. doi: $10.1155 / 2018 / 7218639$

26. Yoon DH, Kang DJ, Kim MJ, Kim HK. New observation of microcystic macular edema as a mild form of cystoid macular lesions after standard phacoemulsification: prevalence and risk factors. Medicine (Baltimore). 2018;97(15):e0355. doi:10.1097/MD.0000000000010355

27. Gandhi JS. Cystoid macular edema after cataract surgery. J Cataract Refract Surg. 2018;44(12):1536. doi:10.1016/j.jcrs.2018.09.014

28. Ibrahim AM, Elgouhary SM, Nassar MK, El Batanony AH. Changes in choroidal thickness after cataract surgery. Semin Ophthalmol. 2018;33(5):664-670. doi:10.1080/08820538.2017.1416410

29. Jiang H, Li Z, Sun R, Liu D, Liu N. Subfoveal choroidal and macular thickness changes after phacoemulsification using enhanced depth imaging optical coherence tomography. Ophthalmic Res. 2018;60 (4):243-249. doi:10.1159/000480240

30. Biro Z, Balla Z, Kovacs B. Change of foveal and perifoveal thickness measured by OCT after phacoemulsification and IOL implantation. Eye (Lond). 2008;22(1):8-12. doi:10.1038/sj.eye.6702460

31. Yilmaz T, Yilmaz A. Long-term changes in subfoveal choroidal thickness and central macula thickness after Nd:YAG laser capsulotomy. Int Ophthalmol. 2017;37(4):1003-1008. doi:10.1007/ s10792-016-0353-x
32. Gharbiya M, Cruciani F, Cuozzo G, Parisi F, Russo P, Abdolrahimzadeh S. Macular thickness changes evaluated with spectral domain optical coherence tomography after uncomplicated phacoemulsification. Eye (Lond). 2013;27(5):605-611. doi:10.1038/ eye. 2013.28

33. Edelhauser HF. Functional survival of cryopreserved corneal tissue. In: Capella JA, Edelhauser HF, Van HornDL(eds)Corneal Preservation. Springfield: Thomas. 1973,280-286.

34. Hoffman J. Cold irrigating solution in cataract surgery may make for quieter eyes. Insight. 1991;16(2):11.

35. Praveen MR, Vasavada AR, Shah R, Vasavada VA. Effect of room temperature and cooled intraocular irrigating solution on the cornea and anterior segment inflammation after phacoemulsification: a randomized clinical trial. Eye (Lond). 2009;23(5):1158-63. doi:10.1038/ eye.2008.187.

36. Perente I, Utine CA, Ozturker C, et al. Evaluation of macular changes after uncomplicated phacoemulsification surgery by optical coherence tomography. Curr Eye Res. 2007;32(3):241-247. doi:10.1080/ 02713680601160610

37. Kusbeci T, Eryigit L, Yavas G, Inan UU. Evaluation of cystoid macular edema using optical coherence tomography and fundus fluorescein angiography after uncomplicated phacoemulsification surgery. Curr Eye Res. 2012;37(4):327-333. doi:10.3109/ 02713683.2011.635402

38. Xu H, Chen M, Forrester JV, Lois N. Cataract surgery induces retinal pro-inflammatory gene expression and protein secretion. Invest Ophthalmol Vis Sci. 2011;52(1):249-255. doi:10.1167/iovs.10-6001

39. Yüksel B, Karti Ö, Kusbeci T. Topical nepafenac for prevention of post-cataract surgery macular edema in diabetic patients: patient selection and perspectives. Clin Ophthalmol. 2017;11:2183-2190. doi:10.2147/OPTH.S132810
Clinical Ophthalmology

\section{Publish your work in this journal}

Clinical Ophthalmology is an international, peer-reviewed journal covering all subspecialties within ophthalmology. Key topics include: Optometry; Visual science; Pharmacology and drug therapy in eye diseases; Basic Sciences; Primary and Secondary eye care; Patient Safety and Quality of Care Improvements. This journal is indexed on PubMed

\section{Dovepress}

Central and CAS, and is the official journal of The Society of Clinical Ophthalmology (SCO). The manuscript management system is completely online and includes a very quick and fair peer-review system, which is all easy to use. Visit http://www.dovepress.com/ testimonials.php to read real quotes from published authors. 